\title{
Conexão de Saberes: a experiência interdisciplinar do Programa de Educação Tutorial Comunidades do Campo da UFPR
}

\author{
Liliani Marilia Tiepolo ${ }^{1}$ \\ Valdir Frigo Denardin ${ }^{2}$ \\ Pedro Sarkis Simões de Oliveira ${ }^{3}$ \\ Erica Vicente Onofre ${ }^{4}$ \\ Emanuel Rodrigues Cardoso 5 \\ Elisama Dias ${ }^{6}$ \\ Valkiria Spring ${ }^{7}$ \\ Carlos Claudio Costa ${ }^{8}$ \\ Andressa Luz Borges ${ }^{9}$ \\ Valner Wasilewski da Silva ${ }^{10}$ \\ Cleonice Schull da Cruz ${ }^{11}$ \\ Matheus Santana Antiquera ${ }^{12}$ \\ Gabriel Rodrigues Lima ${ }^{13}$
}

A partir das conexões de saberes instituídas como um novo eixo dentro dos Programas de Educação Tutorial, surge o grupo PET Comunidades do Campo em 2010, na expansão da Universidade Federal do Paraná, criada em 2005 no litoral do estado. As atividades do grupo se dão em torno de temas relacionados ao modo de vida do campo, agroecologia, agricultura familiar, território e desenvolvimento rural, onde a característica predominante é a interdisciplinaridade, tendo em vista que faz parte de uma política pública que tem por objetivo agregar diversos conhecimentos e saberes ao tema. O PET Comunidades do Campo da UFPR é composto por 14 integrantes. Os estudantes são distribuídos entre os cursos de Tecnologia em Agroecologia, Gestão Ambiental, Gestão e Empreendedorismo, Gestão Pública, Saúde Coletiva e Licenciatura em Educação Física. Aqui traçamos um panorama das representações que estes estudantes têm sobre interdisciplinaridade a partir de algumas questões abertas a eles direcionadas. O resultado evidencia, que o conhecimento interdisciplinar faz parte de suas reflexões e práticas tanto na vida acadêmica quanto em suas relações cotidianas. Destacamos também que o ambiente universitário local favorece, em alguns espaços e para alguns cursos, a troca de saberes e o compartilhamento de informações e conhecimentos, mas o PET Comunidades do Campo proporciona o efetivo exercício da interdisciplinaridade, ampliando os horizontes de possibilidades das profissões escolhidas.

Palavras-chave: PET, Interdisciplinaridade, Educação

From the connections of knowledge instituted as a new axis within the Tutorial Education Programs, the PET Rural Communities group emerges in 2010, in the expansion of the Federal University of Paraná, created in 2005 in the coast of the state. The activities of the group take place around themes related to the rural life, agroecology, family farming, territory and rural development, where the predominant characteristic is

\footnotetext{
${ }^{1}$ Universidade Federal do Paraná, Setor Litoral

${ }^{2}$ Universidade Federal do Paraná

${ }^{3}$ Universidade Federal do Paraná

${ }^{4}$ Universidade Federal do Paraná

${ }^{5}$ Universidade Federal do Paraná

${ }^{6}$ Universidade Federal do Paraná

${ }^{7}$ Universidade Federal do Paraná

${ }^{8}$ Universidade Federal do Paraná

${ }^{9}$ Universidade Federal do Paraná

${ }^{10}$ Universidade Federal do Paraná

${ }^{11}$ Universidade Federal do Paraná

12 Universidade Federal do Paraná

${ }^{13}$ Universidade Federal do Paraná
} 
interdisciplinarity, since it is part of a public policy aimed academic and popular knowledge about this themes. The PET Rural Communities of the UFPR is composed of 14 members. The students are distributed among the courses of Technology in Agroecology, Environmental Management, Management and Entrepreneurship, Public Management, Collective Health and Licentiate in Physical Education. Here we draw a panorama of the representations that these students have about interdisciplinarity from some questions open to them. The results evidences that interdisciplinary knowledge is part of his reflections and practices both in academic life and in his everyday relationships. We also emphasize that the local university environment favors the exchange of knowledge and the sharing of information and knowledge, expanding the horizons of possibilities of the chosen professions.

Key words: PET, Interdisciplinarity, Education

\section{Introdução}

O Programa de Educação Tutorial (PET) é um programa governamental nacional, subsidiado pelo Ministério da Educação e Cultura (MEC) e pela Secretaria de Ensino Superior (SESu), visando a formação acadêmica e profissional de excelência, através de atividades de Ensino, Pesquisa e Extensão. Atualmente no âmbito nacional existem 842 grupos PET distribuídos entre 121 Instituições de Ensino Superior, sendo 22 grupos PET na UFPR.

O programa foi criado para formar profissionais de nível Superior dotados de elevados padrões científicos, técnicos e éticos nas diversas áreas do conhecimento, além de selecionar um grupo de estudantes com interesses em comum: a ampliação dos conhecimentos oferecidos na graduação e o desenvolvimento pessoal. Assim, busca-se uma maior interação entre estudantes participantes do Programa e os corpos discente e docente da Instituição.

O grupo PET Conexões de Saberes Comunidades do Campo, PET Comunidades do Campo, iniciou suas atividades em dezembro de 2010, tendo o professor Valdir Frigo Denardin como seu primeiro tutor. O PET Comunidades do Campo é um grupo interdisciplinar constituído por 13 estudantes, sendo 12 bolsistas, que incluem diversos cursos da instituição. É a partir destas característica que os integrantes desenvolvem atividades das mais diferentes naturezas, como pesquisas individuais e coletivas, organização de eventos, palestras e visitas técnicas (em feiras, propriedades rurais, agroindústrias familiares) e envolvimento político dentro da instituição (congressos do PET, reuniões com outras entidades estudantis ou em esferas administrativas da UFPR). Através dessas atividades, cada um desenvolve diferentes tipos de habilidades, como a criatividade, a autonomia, o comprometimento, a comunicação e a competência.

Consideramos que o desenvolvimento das atividades conjuntas seria um problema se Revista Extensão em Foco, nº 13, Jan/ Jul (2017) p. 78 - 91. 
não fosse a característica interdisciplinar do grupo, inserido em uma matriz interdisciplinar a partir do Projeto Político Pedagógico institucional e dos Projetos Pedagógicos dos Cursos de graduação no Setor Litoral. O objetivo deste trabalho é trazer algumas evidências, a partir do olhar dos estudantes que integram o PET CC, das representações sobre teoria e prática interdisciplinar dentro do grupo e apontar os benefícios para todos seus integrantes no entendimento do mundo. Para tanto, fizemos uma enquete dentro do nosso grupo abordando cinco questões sobre interdisciplinaridade, as quais discutimos ao longo do trabalho.

\section{Material e Métodos}

A partir do entendimento dos estudantes sobre interdisciplinaridade, tendo como desafio as dificuldades de sua implementação no cotidiano de ensino, pesquisa e extensão, aplicou-se um questionário composto de cinco questões aos estudantes que fazem parte do grupo PET Comunidades do Campo, da Universidade Federal do Paraná, Setor Litoral. Outras três questões situavam os estudantes em relação a sua idade, ao tempo em que estão na Universidade, ao tempo em que participam do PET e o curso ao qual pertencem. Ao longo do texto, os estudantes são identificados pelo curso ao qual pertencem e pela idade.

As questões foram as seguintes: 1) Qual a sua compreensão sobre interdisciplinaridade? 2) De que forma você percebe a interdisciplinaridade em suas ações cotidianas, na universidade e nas atividades do PET? 3) Você considera importante exercitar suas reflexões, pensamentos, experiências e ações a partir de uma visão interdisciplinar? Por quê? 4) Qual a maior dificuldade em vivenciar seus estudos, pesquisas e ações a partir de uma perspectiva interdisciplinar? 5) Considerando que o PET Conexões de Saberes é uma experiência acadêmica interdisciplinar, de que forma o PET Comunidades do Campo agrega na sua interpretação de mundo dentro e fora da Universidade?

Uma ressalva se faz importante: tanto o Projeto Político Pedagógico (PPP) do Setor Litoral da UFPR, quanto os Projetos Pedagógicos dos Cursos (PPC) do Setor Litoral, tem por base a interdisciplinaridade. Ou seja, os estudantes constroem seus conhecimentos na universidade a partir da inserção dos sentidos da interdisciplinaridade. Portanto, as questões levantadas aqui captam as representações que os estudantes têm em relação a construção do pensamento interdisciplinar, sem necessariamente terem lido ou estudado sobre o assunto. Alguns cursos do Setor Litoralforam criados a partir de concepções interdisciplinares, como por exemplo Gestão Ambiental, que está inserido na área de Ciências Ambientais, 
interdisciplinar por essência. Os grupos PET existentes no Setor Litoral também foram concebidos dentro da idéia das conexões de saberes.

\section{Resultados}

\section{O contexto interdisciplinar in loco}

Atualmente o PET Comunidades do Campo é composto por 14 integrantes, sendo 12 bolsistas, uma voluntária e a tutora. São acadêmicos dos cursos de Tecnologia em Agroecologia (3), Gestão Ambiental (6), Gestão e Empreendedorismo (1), Gestão Pública (1), Saúde Coletiva (1), Licenciatura em Educação Física (1). Os cursos são distintos, desde tecnológicos como Agroecologia, como bacharelados e licenciaturas. A tutora tem formação na área de Ciências Biológicas e o tutor anterior, criador do grupo PET Comunidades do Campo, tem formação na área de Economia. Estas características promovem o aporte de uma variedade de pontos de vista, visões de mundo e modos de compreensão de determinado problema. Ao contrário do que poderia ser esperado, não há no grupo conflitos dentro das áreas do conhecimento, mas uma ampliação no leque de possibilidades de observar um fenômeno que ocorre a partir dos diálogos promovidos sobre o mesmo, ocorrendo de forma muito espontânea.

O grupo desenvolve ações que visam articular ensino, pesquisa e extensão, a partir de referencial bibliográfico atrelado a um conjunto de ações voltadas para a realidade da agricultura familiar local. As atividades de ensino e pesquisa são desenvolvidas no meio acadêmico, nas instalações da Universidade Federal do Paraná (Setor Litoral), as atividades de extensão têm como finalidade apoiar e propor ações de extensão junto às comunidades rurais. Dessa forma, busca estabelecer mecanismos que relacionam a comunidade acadêmica com o contexto rural local, promovendo uma boa relação entre o meio acadêmico e a Revista Extensão em Foco, nº 13, Jan/ Jul (2017) p. 78 - 91. 
comunidade externa.

A política de "Conexão de Saberes: diálogos entre a universidade e as comunidades populares" estabelecida para o PET em 2006, foi fundamental para o estalecimento de um ambiente interdisciplinar. Com base na Portaria 1/2006 do Ministério da Educação, o Programa visa apoiar projetos inovadores das instituições federais de ensino superior (IFES) voltados a assegurar a permanência dos estudantes oriundos de espaços populares, mediante a consecução dos seguintes objetivos: I - ampliar a relação entre a universidade e os moradores de espaços populares, assim como com suas instituições; II - criar estruturas institucionais e pedagógicas adequadas à permanência de estudantes de origem popular na universidade e à democratização do acesso ao ensino superior; III - aprofundar a formação dos jovens universitários de origem popular como pesquisadores e extensionistas, visando sua intervenção qualificada em diferentes espaços sociais, em particular, na universidade e em comunidades populares; IV - implantar ações e projetos de assistência integral aos grupos sociais em situação mais crítica de vulnerabilidade social, em particular crianças e jovens; V coletar, sistematizar e analisar dados e informações sobre a estrutura universitária e as condições de acesso e permanência dos estudantes universitários de origem popular nos cursos de graduação; e VI - estimular a formação de novas lideranças capazes de articular competência acadêmica com compromisso social.

Ou seja: objetiva desenvolver ações inovadoras que ampliem a troca de saberes entre as comunidades populares e a universidade, valorizando o protagonismo dos estudantes universitários beneficiários das ações afirmativas no âmbito das Universidades públicas brasileiras, contribuindo para a inclusão social de jovens oriundos das comunidades do campo, quilombola, indígena e em situação de vulnerabilidade social.

\section{Representações sobre interdisciplinaridade}

Ao serem questionados sobre a compreensão do conceito, alguns estudantes o abordam como a troca de conhecimentos entre disciplinas de diversas maneiras. O estudante de Agroecologia, de 21 anos, o compreende como "comunhão de diversas áreas do conhecimento que se aproximam na perspectiva de unir conhecimentos diversos em foco de algo em comum". Na mesma direção vai o estudante de Educação Física, de 22 anos, para o qual o conceito "agrega diferentes conhecimentos e ideias a cerca de um mesmo assunto." Continua: "é buscar para um só problema, diversas formas de resolução através dos mais variados e diferentes tipos de pessoas.”. O estudante de 20 anos de Gestão e 
Empreendedorismo afirma: "Acredito que alguns cursos vivenciam com maior amplitude a interdisciplinaridade, por serem vertentes desta, como saúde coletiva, agroecologia e o empreendedorismo." Nesta direção, a estudante de Saúde Coletiva, de 19 anos, afirma que a interdisciplinaridade "é relação de diálogo e convivência entre diferentes disciplinas, ou entre pessoas de diferentes áreas".

A estudante de 21 anos, de Gestão Ambiental, entende a mudança de ponto de vista a partir da troca interdisciplinar: "a junção de diversas matérias, áreas ou setores para o entendimento de um determinado acontecimento, possibilita a modificação do mesmo, após a troca interdisciplinar. A interdisciplinaridade está bem distante da exatidão, sendo capaz de enriquecer o conhecimento".

Já o estudante de 24 anos de Agroecologia aponta a crítica às ciências e traz a concepção interdisciplinar para o olhar holístico: “a interdisciplinaridade é uma maneira de superarmos o modo cartesiano de dividir o trabalho (intelectual e braçal), a qual, coloca cada área do saber dentro de sua 'caixa' e nos diz que para compreendermos o todo, precisamos dividir as tarefas em quantas partes forem necessárias. Porém podemos compreender através do processo histórico que a ciência traçou, que isso não é suficiente. Com isso, a interdisciplinaridade vem transcender esta concepção, e criar novas possibilidades de aprendizado e realização de tarefas, tendo um olhar mais holístico sobre os processos de construção e realização das mesmas."

Portanto, está bem clara na concepção do conceito por parte dos estudantes a idéia de junção, mescla, convivência, conjunção, comunhão, agregação, entrelaçamento, diálogo e diversidade de olhares e ângulos em convergência entre conhecimentos - que se pretende holístico, mas que encontra-se compartimentalizado.

Este tem sido um tema constante em diversas áreas do conhecimento. Minayo (1994), por exemplo, ao tratá-lo, expõem que "nossas indagações contemporâneas são a reafirmação da utopia de uma integridade perseguida historicamente pela ciência" (p. 1). Completa, dizendo que "A preocupação dos grandes sábios tem sido a de que a dispersão de conhecimento, se corresponde à divisão de trabalho intelectual, não deveria resultar em contradições entre os pesquisadores e o resultado de seus trabalhos". A autora investiga o conceito a partir de sua visão na área de saúde, assumindo que "a reivindicação interdisciplinar ora se apresenta como panacéia epistemológica, invocada para curar todos os Revista Extensão em Foco, nº 13, Jan/ Jul (2017) p. 78 - 91. 
males que afetam a consciência científica moderna; por vezes se fala dela com um ceticismo radical; por vezes, como uma fatalidade própria do avanço técnico e científico.”

A necessidade da interdisciplinaridade na produção e na socialização do conhecimento no campo educativo vem sendo discutida por vários autores, principalmente por aqueles que pesquisam as teorias curriculares e as epistemologias pedagógicas. Para Thiesen (2008) a literatura sobre esse tema mostra que existe pelo menos uma posição consensual quanto ao sentido e à finalidade da interdisciplinaridade: ela busca responder à necessidade de superação da visão fragmentada nos processos de produção e socialização do conhecimento. Trata-se de um movimento que caminha para novas formas de organização do conhecimento ou para um novo sistema de sua produção, difusão e transferência.

\section{A percepção da interdisciplinaridade nas ações cotidianas da Universidade}

O estudante de Gestão Ambiental, de 21 anos, traz para a compreensão as especificidades do local, diz ele: "o Setor Litoral concentra todos os cursos no mesmo prédio e os estudantes dos cursos frequentam os mesmos espaços e tem trocas de experiências e diálogos de saberes a todo o instante, o que permite se abrir ao pensamento de um outro curso diferente e o considerar na construção de um novo pensamento.” Já a estudante de Gestão Pública, de 28 anos, menciona que "a partir dos princípios que norteiam as atividades do Grupo PET (ensino, pesquisa e extensão), estas são mais dinâmicas, completas e tornam-se mais produtivas com resultados satisfatórios". Para ela "a troca de conhecimentos entre os membros do grupo se torna algo constante, permitindo que os mesmos passem por experiências que os cursos não oferecem".

Ao tratar do assunto, a estudante de Agroecologia, de 19 anos, menciona: "Percebo que a separação entre as disciplinas é um método para tornar mais fácil o aprofundamento em cada uma delas, porém quando se trata de entender um todo de forma mais complexa, a interdisciplinaridade é o modelo ideal." Continua ela: "Como trabalhamos com vários cursos do setor dentro do PET percebe-se a colaboração que cada conhecimento específico pode ter e como isso pode ser potencializado num trabalho conjunto entre estes conhecimentos". Para a estudante de Saúde Coletiva, a interdisciplinaridade dentro do PET é notória, pois congrega uma variedade grande de cursos. "Cada um desses cursos possuem várias especificidades que é compartilhada uns com os outros, enriquecendo o aprendizado".

Já o estudante de Agroecologia (24 anos) aponta que seu curso já é interdisciplinar em si e que "depende necessariamente da construção de espaços interdisciplinares, que pretendem 
ser em si uma área que transcende a divisão de tarefas em partes desconexas". Cita que o Setor Litoral da UFPR “tem o compromisso em promover espaços interdisciplinares dentro dos processos de aprendizagem de todos os cursos ofertados" e que ele, pessoalmente, vive esta busca em todos os espaços que participa na Universidade. Porém, segundo ele, o ‘sucateamento' que o Setor Litoral sofre atinge os espaços físicos e a contratação de docentes interdisciplinares, o que compromete o entendimento e a prática interdisciplinar, com as aulas "se tornando um tanto cartesianas e dentro de suas limitações", mesmo assim, reitera, há construção de espaços interdisciplinares. Já sobre o PET, este é visto como "um importante laboratório de discussão e vivência do que seria a interdisciplinaridade idealmente". Pois, segundo ele "realizamos a todo o tempo atividades de forma interdisciplinar, seja na construção de artigos, nas discussões de textos, atividades de extensão no campo e outros, com estudantes de diferentes cursos e com eles diferentes pontos de vista para o mesmo assunto, resolvendo problemas de forma conjunta, onde cada sujeito pode realizar propostas e intervir nos projetos de acordo com a sua aptidão profissional”.

Aqui temos um contexto muito particular, destacado entre os estudantes: o Setor Litoral da UFPR nasce a partir de uma concepção pedagógica que prevê a troca de conhecimentos de maneira interdisciplinar e proporciona espaços para que de fato isso ocorra, um dos exemplos é o eixo pedagógico denominado Interações Culturais e Humanísticas, que representa parte significativa do curriculum dos estudantes de todos os cursos. Segundo o PPP do Setor Litoral (p. 31), as ICH podem ser assim compreendidas:

O espaço curricular de Interações Culturais e Humanísticas ( $\mathrm{ICH})$ consiste em um dos pilares do Projeto Político Pedagógico da UFPR Litoral, representando, no mínimo, $20 \%$ da carga horária curricular em todos os cursos. Através de encontros que ocorrem semanalmente, integrando estudantes dos diferentes cursos, as ICH constituem-se num espaço de aprendizagem interdisciplinar. Possibilita a articulação de diversos saberes (científicos, culturais, populares e pessoais) e busca um olhar mais amplo para a problemática cultural e humanística contemporânea.

Edgar Morin (2002), em sua obra "A cabeça bem feita: repensar a reforma repensar o pensamento" apresenta que a organização disciplinar instituída no século XIX surgiu juntamente com a formação nas universidades modernas, tendo se desenvolvido ao longo do Revista Extensão em Foco, nº 13, Jan/ Jul (2017) p. 78 - 91. 
século $\mathrm{XX}$, com o impulso dado à pesquisa científica. Para ele, isso significa que "as disciplinas têm uma história: nascimento, institucionalização, evolução, esgotamento, etc. Essa história está inscrita na da Universidade, que, por sua vez, está inscrita na história da sociedade (Morin, 2002, p. 105)."

Já em sua obra "Os sete saberes necessários para a educação do futuro", Morin (2000) enfatiza que as disciplinas, como estão estruturadas, só servirão para isolar os objetos do seu meio e isolar partes de um todo. Segundo ele, a educação deve romper com essas fragmentações para mostrar as correlações entre os saberes, a complexidade da vida e dos problemas que hoje existem. Caso contrário, será sempre ineficiente e insuficiente para os cidadãos do futuro. Diz ele: "a inteligência parcelada, compartimentada, mecanicista, disjuntiva e reducionista rompe o complexo do mundo em fragmentos disjuntos, fraciona os problemas, separa o que está unido, torna unidimensional o multidimensional" (Morin, 2000, p. 43).

O PET Comunidades do Campo, por agregar estudantes de diversos cursos, tem em sua trajetória a perspectiva interdisciplinar, fortemente observada entre os estudantes que responderam às perguntas. A partir do lugar onde está inserido o PET e do modo de trabalho do grupo, o espaço contribui de maneira muito eficaz para que o ensino, a pesquisa e a extensão estejam indissociados nas suas atividades. Neste contexto, a experiência interdisciplinar de fato ocorre, uma vez que são inseridos temas de estudo, pesquisa, debate e práticas, que passam a ser analisados a partir de uma diversidade de olhares dentro do grupo. Para Thiesen (2008), no campo conceitual, a interdisciplinaridade será sempre uma reação alternativa à abordagem disciplinar normalizadora (seja no ensino ou na pesquisa) dos diversos objetos de estudo. Independente da definição que cada autor assuma, a interdisciplinaridade está sempre situada no campo onde se pensa a possibilidade de superar a fragmentação das ciências e dos conhecimentos produzidos por elas e onde simultaneamente se exprime a resistência sobre um saber parcelado.

\section{A importância do pensar interdisciplinar}

O mundo não é feito de apenas uma área, as pessoas não possuem um único olhar em relação ao mundo. Não podemos nos fechar em uma única temática. Esta reflexão, da estudante de Saúde Coletiva (19 anos) vai além: “O mundo sofre hoje com os reflexos do sistema biomédico, que desconsidera áreas como saneamento, educação, habitação e lazer 
como determinantes para a saúde". A estudante de Agroecologia, de 19 anos, menciona a importância de exercitar a reflexão interdisciplinar: "a visão direcionada e específica dentro de uma linha de conhecimento é muito limitada e tem pouca relação com a complexa realidade".

Para o estudante de Gestão Ambiental, de 21 anos, a importância de exercitar reflexões, pensamentos, experiências e ações se dá "pela tendência constante em ver as coisas de forma compartimentalizada, individualizada e 'engessada'. A partir do momento em que você se liberta dessas amarras e começa a realizar conexões entre os diferentes saberes, proporciona novos horizontes a partir da conexão do ponto em comum entre os conhecimentos". Do mesmo curso, outra estudante sinaliza: “interdisciplinaridade proporciona troca e expansão".

Para o acadêmico de Educação Física, "apenas quando tentamos analisar uma situação ou assunto dos mais variados 'lados' é que temos condições de opinar e ter convicção do que defender. A interdisciplinaridade vem para nos ajudar a entender o todo e não somente aquilo que é familiar".

Neste ponto, observamos que o grupo percebe claramente os diversos mecanismos que estão atrelados ao modo disciplinar de pensar e suas consequências para a sociedade moderna. Também evidenciam a importância da reflexão interdisciplinar como uma abertura de horizontes, e até mesmo uma libertação para tratar de assuntos que vão desde o cotidiano de suas vidas, até temas complexos contemporâneos. Os temas de estudo, tanto individual, quando coletivos e os diálogos e debates presentes do cotidiano do grupo também se movimentam com facilidade na perspectiva interdisciplinar. A partir deste contexto levantado pelos estudantes, nos serve bem os escritos de Japiassu (1976), um dos precursores da abordagem interdisciplinar no Brasil. Ele menciona em sua clássica obra "Interdiscipliaridade e patologia do saber" que a interdisciplinaridade caracteriza-se pela intensidade das trocas entre os especialistas e pelo grau de integração real das disciplinas no interior de um mesmo projeto. A interdisciplinaridade visa à recuperação da unidade humana pela passagem de uma subjetividade para uma intersubjetividade e, assim sendo, recupera a idéia primeira de cultura na formação do ser humano total, o papel da escola na formação do ser humano inserido em sua realidade e o papel do ser humano como agente das mudanças do mundo.

Revista Extensão em Foco, nº 13, Jan/ Jul (2017) p. 78 - 91. 


\section{Dificuldades e limitações}

Quando levantadas as dificuldades e limitações na vivência interdisciplinar, o estudante de Agroecologia, 24 anos, é enfático: "Como sempre aprendemos a trabalhar de forma cartesiana, individualista e meritocrática. Creio que a maior dificuldade está em desconstruir alguns 'modos de pensar' que nos aprisionam em nossa individualidade e não nos permitem participar e nos expressar de forma plena para resolver problemas conjuntamente com profissionais de diferentes áreas". Na mesma linha de raciocínio segue o estudante de Educação Física: "Ao chegar na Universidade, adentramos em um mundo desconhecido, com diversas situações nunca vivenciadas. Temos de estar dispostos a interagir e entender as razões e os motivos para compreender. Acredito que este seja o ponto mais dificultoso: deixar nossas concepções de lado, para que assim tenhamos condições de realmente olhar de forma diferente. Nos permitir a enxergar com desconfiança o que até então era tido como totalmente certo, sem dúvidas é o que mais dificulta."

A estudante de Gestão Pública, traz a dificuldade para as relações práticas de extensão entre pesquisadores e comunidade. Para ela "necessitamos conhecer a realidade e compartilhar diferentes aprendizagens e conhecimentos para poder conciliar resultados que visem a melhoria da qualidade de vida dessas comunidades que muitas vezes não possuem acesso as informações, e devemos buscar respeitar suas tradições".

Trazendo para o campo dos estudos, o estudante de Gestão e Empreendedorismo reforça a ideia que a "maior dificuldade é a facilidade de dispersão, uma vez que a interdisciplinaridade proporciona visão mais complexa, múltiplas atrações por diversos assuntos podem se tornar uma armadilha se não houver foco.” Mesma visão é compartilhada pela acadêmica de Agroecologia (19 anos), para a qual "é difícil manter uma linha de raciocínio clara, devido à abrangência de temas e possibilidades". Já a estudante de Gestão Ambiental (21 anos) salienta que por 19 anos viveu sem participar de exercícios desta natureza, e que sua maior dificuldade é na análise dos fatos.

A estudante de Saúde Coletiva traz a interdisciplinaridade não como uma dificuldade mas como um desafio, especialmente em relação ao respeito ao olhar diferenciado que cada pessoa possui. Neste mesmo sentido, o estudante de Gestão Ambiental (20 anos) aponta que “o trabalho em grupo já é difícil, trabalhar sobre diversos pontos de vista gera conflitos, pois dependendo do olhar, ele pode se sobrepor ao olhar de outra perspectiva. O relato de outro estudante de Gestão Ambiental (21 anos) traz uma conciliação: "Talvez a maior dificuldade é 
realmente encontrar o ponto em comum entre os conhecimentos diversos para a construção de um novo conhecimento, desta vez interdisciplinar, que contemplem ambas (ou mais) áreas nessa construção. Sendo necessária uma discussão mais aprofundada entre as áreas para que se possa encontrar pontos de convergência e que estes proporcionem o novo conhecimento".

A acadêmica de Gestão Ambiental (26 anos) sintetiza: "Temos que sair de uma zona de conforto. Ir para além do nosso conhecimento. Dialogar com outras opiniões que podem ser opostas às nossas e entrar num comum acordo".

Passadas décadas, desde que esta abordagem chegou ao Brasil, Ivani Fazenda resume bem a prática interdisciplinar no país: "Embora a implementação da prática interdisciplinar esteja em voga na educação brasileira, a insegurança e a dificuldade de realizar projetos dessa natureza ainda impera entre os educadores (Fazenda, 2002). Para ela, uma atitude interdisciplinar respeita a autonomia de vôo de cada um, pois acredita que o estabelecimento da marca do pesquisador, que o torna único e lhe confere autonomia, está na forma como estabelece parceria (Fazenda, 2003). Neste aspecto atitudinal, Trindade (2008, p. 73) nos brinda com sua concepção de interdisciplinaridade como sendo, que, de uma forma ou de outra, apareceram em todas as respostas dos estudantes sobre o tema:

\begin{abstract}
Uma atitude de humildade diante dos limites do saber próprio e do próprio saber, sem deixar que ela se torne um limite; a atitude de espera diante do já estabelecido para que a dúvida apareça e o novo germine; a atitude de respeito ao olhar o velho como novo, ao olhar o outro e reconhecê-lo, reconhecendo-se; a atitude de cooperação que conduz às parcerias, às trocas, aos encontros, mais das pessoas que das disciplinas, que propiciam as transformações, razão de ser da interdisciplinaridade. Mais que um fazer, é paixão por aprender, compartilhar e ir além.
\end{abstract}

\title{
Conclusão
}

Os petianos são unânimes em suas experiências interdisciplinares ao agregar novos elementos para suas interpretações de mundo. Consideram o ambiente criado na Universidade (Setor Litoral) como propício para o diálogo, compartilhamento de opiniões e análises do mundo. A partir de suas experiências são notáveis as trocas de conhecimento para se chegar a um denomidador comum. Podemos considerar que a reflexão proporcionada por temas escolhidos de maneira individual e os temas desenvolvidos de forma coletiva, bem como 
aqueles tratados nos cotidiano do grupo e em suas visitas técnicas, fazem parte de uma escolha metodológica, que proporciona a experiência interdisciplinar.

O respeito a opinião do colega é enfatizado por todos como um aprendizado nesta perspectiva, saber ouvir, em especial em relação aos trabalhos em equipe. Para eles, interpretar o mundo contemporâneo exige diversos olhares, fruto de diferentes disciplinas, pensamentos e reflexões, respeitando a diversidade e buscando unir esforços.

A formação crítica é outro destaque levantado, uma vez que um dos objetivos do Programa é a formação de pessoas capazes de formar suas próprias opiniões de mundo a partir de diversas opiniões, conhecimentos e vivências. É unânime também o ideal de que a partir de visões abertas a novos conhecimentos compartilhados, é possível transformar a realidade.

Podemos considerar, a partir desta experiência, que a política estabelecida com a conexão de saberes, ampliando o Programa de Educação Tutorial é exitosa em sua concepção, uma vez que está contribuindo para formar novos profissionais, com visões renovadas sobre a ciência, o conhecimento e os saberes necessários para conviver neste mundo.

\section{Agradecimentos}

Agradecemos aos organizadores e coordenadores da Semana Integrada de Ensino, Pesquisa e Extensão da Universidade Federal do Paraná, por proporcionarem aos estudantes, orientadores e tutores a participação no Encontro das Atividades Formativas, edição 2016. Nossos agradecimentos especiais ao Ministério da Educação, por meio de sua Secretaria de Educação Superior por fomentarem com bolsas e custeios o Programa de Educação Tutorial Comunidades do Campo da UFPR.

\section{Referências bibliográficas}

FAZENDA, I. C. A. Interdisciplinaridade: história, teoria e pesquisa. Campinas: Papirus, 2002.

FAZENDA, I. C. A. A Avaliação no pós-graduação sob a ótica da interdisciplinaridade. Pp. 23-28. In: Queluz, A. G. (Org.). Interdisciplinaridade: formação de profissionais da educação. São Paulo: Pioneira Thomson Learning, 2003.

JAPIASSU, H. Interdisciplinaridade e patologia do saber. Rio de Janeiro: Imago, 1976.

MINAYO, M. C. de S. Interdisciplinaridade: funcionalidade ou Utopia? Saúde e Sociedade, v. 3, n. 2, p. 42-64, 1994. 
MINISTÉRIO DA EDUCAÇÃO. Portaria 1 de 17 de maio de 2006.

MORIN, E. Os sete saberes necessários à educação do futuro. São Paulo: Cortez, 2000.

MORIN, E. A cabeça bem feita: repensar a reforma repensar o pensamento. Rio de Janeiro: Bertrand Brasil, 2002.

THIESEN, J. da S. A interdisciplinaridade como um movimento articulador no processo ensino-aprendizagem. Revista Brasileira de Educação, v. 13, n. 39, p. 545-554, 2008.

TRINDADE, D. F. Interdisciplinaridade: um olhar sobre as ciências. P. 65-83. In: Fazenda, I. (Org.). O que é interdisciplinaridade. São Paulo: Cortez, 2008. 